\title{
Entre a razão e a emoção: a tomada de crédito consignado pelos idosos
}

\author{
Bruna Osvald de Souza*, Cleide Fátima Moretto*
}

\section{Resumo}

Os estudiosos da psicologia econômica vêm tentando estabelecer a relação entre o consumo e o comportamento. Compreender as emoções que as pessoas experienciam e as influências, na hora de consumir, ou de postergar o consumo torna-se fundamental quando se analisa a tomada de decisão. O crédito consignado tem sido uma modalidade de empréstimo muito utilizada pelos idosos e, se por um lado sinaliza acesso fácil, por outro implica em endividamento. O objetivo do artigo é verificar os motivos que levam o aposentado a tomar o crédito consignado. $\mathrm{O}$ estudo descritivo tem abordagem qualitativa e apresenta a análise de conteúdo resultante de 12 entrevistas realizadas com idosos aposentados que haviam tomado crédito consignado no município de Não-Me-Toque (RS). Conclui que os aposentados pesquisados tem incorporado a possibilidade de tomar o crédito consignado como uma escolha cotidiana e declaram ser autônomos na decisão, ainda que na maior parte das vezes assumam o endividamento para auxiliar familiares que estão em dificuldade. O sistema afetivo e a solidariedade econômica no âmbito da família influenciam de forma significativa na tomada de decisão.

Palavras-chave: Envelhecimento Humano. Psicologia Econômica. Crédito Consignado. Endividamento.

\section{Introdução}

É crescente o número de aposentados da previdência social no Brasil que recorre ao empréstimo consignado 1 . O crédito, que mais tarde foi chamado de crédito consignado, é muito utilizado, principalmente pelos aposentados e pensionistas do Instituto Nacional do Seguro Social (INSS), como destacam Rodrigues et al. (2005). O valor tomado é descontado diretamente do benefício previdenciário

* Bacharel em Ciências Econômicas pela Universidade de Passo Fundo. Endereço: Rua Pedro Augustin n⿳0 220, Não-Me-Toque (RS) - CEP 99470-000 E-mail: bruna_o_s@hotmail.com.

** Economista. Mestre em Economia (Ufrgs). Doutora em Teoria Econômica (USP). Professora titular da Faculdade de Ciências Econômicas, Administrativas e Contábeis (Feac) e docente permanente do Programa de Pós-Graduação em Envelhecimento Humano (ppgEH), Universidade de Passo Fundo (UPF). E-mail: moretto@upf.br.

$\rightarrow$ http://dx.doi.org/10.5335/rbceh.2014.3978

Recebido em: 19/05/2014. Aprovado em: 01/08/2014 
e não deverá ultrapassar 30,0\% do valor do benefício total. Os autores observam que várias pesquisas foram realizadas, visando mapear as motivações dos empréstimos e apontaram que a finalidade dos recursos advindos de empréstimos consignados seria o pagamento de dívidas, contraídas com juros mais elevados, e para o consumo. Porém, como qualquer modalidade de crédito, alertam os autores, o crédito consignado pode gerar o endividamento, resultando em efeitos adversos, inclusive risco moral ${ }^{2}$. No caso do aposentado ou pensionista, como não existe rescisão de contrato, o valor possui melhor retorno por parte das instituições financeiras. $\mathrm{O}$ apelo ao aposentado, normalmente pessoa idosa, tem sido rotineiro nos correspondentes bancários em geral.

Ainda que a alusão aos aposentados não implique necessariamente tratar de pessoa idosa, observa-se uma aproximação da condição de aposentado às pessoas com mais de 60 anos de idade. Schneider e Irigaray (2008) afirmam que, ainda que os estudiosos da área classifiquem os indivíduos em três categorias de idosos, idosos jovens (65-74 anos), idosos velhos (75 a 84 anos) e idosos mais velhos (mais de 85 anos), o envelhecimento não é determinado apenas pelo aspecto cronológico, mas resulta de experiências passadas, do modo como os indivíduos vivem, se são capazes de gerirem a própria vida no presente e de suas expectativas futuras. Portanto, prevê a integração entre as vivências pessoais e o contexto social e cultural, envolvendo naturalmente diferentes aspectos, cronológicos, biológicos, psicológicos e culturais. $\mathrm{Ca}-$ marano e Pasinato (2004) destacam que para os formuladores de políticas sociais predominam tanto aspectos relacionados com a condição em determinada idade de sua vida quanto em algum ponto do ciclo de vida social.

A velhice, fase em que grande parte dos aposentados está incluída, como destacam Almeida, Mochel e Oliveira (2011), deve ser estudada e compreendida, considerando a sua multidimensionalidade e a forma que essas pessoas convivem com mudanças físicas, cognitivas, de papéis sociais e familiares, de perdas e ganhos, no ambiente sociocultural onde ela é vivenciada. É justamente nessa fase de perda de autonomia, na qual a família, principalmente os filhos, passa a ter um papel fundamental nas decisões relacionadas ao idoso. Saad (2004, p. 170) afirma que, enquanto ocorre uma intensificação do processo de envelhecimento populacional, confirma-se que no Brasil existe um contexto de medidas limitativas à transferência de ajuda de filhos adultos a pais idosos, instalando-se uma situação de dependência do idoso em relação à família que começa a tornar-se motivo de especial preocupação.

Os filhos são os primeiros para quem os idosos pedem auxílio para lhe darem suporte, mas quando esses não podem ajudá-los, por diferentes motivos, os idosos acabam buscando ajuda com amigos e vizinhos. Percebe-se que a questão financeira está ligada à saúde e à aposentadoria e, mesmo sendo uma renda limitada, é ela quem garante o mínimo de autonomia (LIMA; SILVA; GALHARDONI, 2008). Argumentam que, no caso brasileiro, os idosos, ao invés de contarem com os 
benefícios das redes de apoio, são cada vez mais importantes nos domicílios que reúnem três ou mais gerações, sendo responsáveis pela manutenção das despesas e pelo suporte para gerações mais jovens. A família que acolhe o idoso, como argumentam Camarano et al. (2004b, p 152), também usufrui de sua aposentadoria, ou seja, quando o idoso introduz sua renda no ambiente familiar onde está inserido, há um aumento no orçamento da família que está associado ao crescimento da participação do benefício social na sua renda.

Ao falar sobre a família, Camarano, Kanso e Mello (2004a) afirmam que essa pode ser considerada uma das instituições mais importantes e eficientes em relação ao bem-estar do indivíduo e, também, à distribuição de recursos entre os seus membros. Para as autoras, a família serve como base e, na mesma lógica das relações entre o mercado e os indivíduos, atua por meio da intermediação de recursos, ou das relações entre o Estado e o indivíduo, redistribuindo renda direta e indiretamente.

Pode-se deduzir que uma maior atenção deve ser oferecida aos idosos, não somente no ambiente familiar, mas também por parte das instituições de crédito e a sociedade em geral. No que diz respeito à preocupação com o bem-estar, como argumentam Ceshin, Alquati e Ximenes (2012, p.2), "resultados de pesquisas apontam que, tanto para os homens como as mulheres, para viver com qualidade o idoso precisa, além de ter saúde, participar das atividades de lazer e ter boas condições financeiras". Portanto, a dimensão financeira é determinante da qualidade de vida dos idosos.
As escolhas individuais são subjetivas, influenciadas por características pessoais e pela experiência passada. Qualquer indivíduo, em sua fase de criança, adolescente ou adulto, é afetado, como qualquer ser humano, por fatores ligados ao seu sistema psicológico: com o idoso não é diferente. Os estudiosos da psicologia econômica ${ }^{3}$ vêm tentando estabelecer a relação entre o consumo e o comportamento. Compreender as emoções que as pessoas experienciam na hora de consumir, ou de postergar o consumo torna-se fundamental quando se analisa o processo de tomada de decisão. Como defende Katona, um dos pioneiros da psicologia econômica, "o consumidor é um ser humano influenciado pela sua experiência passada. Suas normas socioculturais, atitudes, e hábitos, assim como o seu pertencimento a grupos, todos influenciam suas decisões" (1976, p. 218, tradução nossa). Ao tratar do que o autor denomina "família moderna" como atributo para consumidor, Katona destaca que a tomada de decisão é normalmente uma questão familiar, na qual os membros importam, assim como os estágios do ciclo de vida e renda, o que define a quantidade de bens comprados e a adequação dos meios disponíveis para prover as necessidades de despesas. Esses fatores são avaliados também em relação à tomada de crédito.

O município de Não-Me-Toque, localizado no estado do Rio Grande do Sul, tem uma população de $15.936 \mathrm{mil}$ habitantes (IBGE, 2011). Desses, 2.255 $(14,1 \%)$ tem mais de 60 anos de idade. Com a ampliação do acesso ao crédito por meio do empréstimo consignado, 
observa-se que os aposentados reagem ao endividamento como reagem em relação às demais tomadas de decisão de seu cotidiano. $\mathrm{O}$ estudo, nesse sentido, recai sobre o contexto do idoso aposentado, tratando da peculiaridade desses em termos da tomada de crédito consignado, suas características pessoais, a estrutura familiar e a motivação como aspectos definidores de suas escolhas.

O objetivo central deste trabalho é evidenciar o comportamento dos aposentados em termos de acesso e endividamento pelo crédito consignado do INSS. Questiona-se sobre os motivos econômicos e psicológicos que levam o idoso a assumir o crédito consignado.

\section{Métodos e técnicas}

$\mathrm{O}$ presente artigo apresenta um recorte parcial de uma pesquisa mais ampla, em nível descritivo, que, a partir de uma abordagem qualitativa, buscou delinear o modelo de tomada de decisão de George Katona (1976), para identificar os motivos de acesso e endividamento pelo crédito consignado por parte dos aposentados do INSS. O modelo de Katona pressupõe que as variáveis psicológicas são variáveis intermediárias entre estímulos psicológicos e respostas comportamentais em três instâncias: a primeira $(\mathrm{E})$ corresponde às condições e situações econômicas objetivas, tais como recessão, taxa de desemprego. A segunda $(\mathrm{P})$ corresponde às características pessoais dos agentes econômicos, tais como as aspirações, as expectativas e os estilos de vida. E a terceira (C) corresponde aos comportamentos de compra, a utilização e disposição de bens e serviços. Focalizam-se as características pessoais, o background familiar e a finalidade do crédito dos aposentados pesquisados.

Inicialmente, busca-se identificar as características pessoais, como idade, gênero, escolaridade, renda bruta mensal, estado civil, situação da unidade familiar, número de dependentes. Uma categoria utilizada para a compreensão do processo de tomada de decisão de crédito é o background familiar. Nessa categoria buscam-se identificar como as atitudes, a cultura, os hábitos que esse indivíduo teve ao longo de sua trajetória pessoal interferem na vida financeira e na decisão do crédito na atualidade. Por fim, a categoria que irá determinar a causalidade entre a tomada de crédito e a situação de endividamento dos aposentados é a finalidade do crédito. Com essa categoria, a intenção é identificar quais são as causas e para aonde vai o recurso financeiro, se é para o próprio consumo ou se é para auxiliar outros membros da família.

O levantamento de dados seguiu uma amostragem não probabilística, por cotas e intencional. A inclusão dos participantes foi gradual, buscando características distintas. Os participantes foram abordados nas agências bancárias locais, questionados sobre o fato de serem aposentados, de terem tomado crédito consignado e interesse e disponibilidade em participar do estudo. Os aposentados que responderam afirmativamente foram cientificados dos objetivos estritamente acadêmicos da pesquisa e da segurança e do anonimato de suas identidades. Com a permissão, receberam, leram e assi- 
naram o termo de consentimento livre e esclarecido ${ }^{4}$. O instrumento de pesquisa foi a entrevista em profundidade, por meio de um roteiro de questões abertas. As entrevistas, realizadas nos meses de setembro e outubro de 2012, foram gravadas, transcritas e citadas conforme $o$ grau de importância para a análise dos dados. As falas, resultantes das entrevistas, foram analisadas por meio da analise de conteúdo de Bardin (2000).

\section{Resultados e discussão}

Os resultados apresentados referem-se aos aposentados pesquisados e recaem em suas peculiaridades, similaridades e diferenças observadas. No total foram entrevistados doze aposentados, todos beneficiários do INSS e que possuem empréstimos consignados, conforme o critério adotado para a inclusão na pesquisa. Cada um dos entrevistados, para garantir o anonimato de sua participação, foi identificado por letras alfabéticas (B, D, R, N, E, X, J, L, I, O, P) e associados ao gênero (homem, mulher) $\mathrm{e}$ à idade. As falas preservam a linguagem utilizada pelos participantes e representam o seu relato livre, a partir das questões colocadas pelo entrevistador.

\section{Características pessoais}

Buscou-se, com a categoria características pessoais, examinar possíveis diferenças na tomada de crédito, em função da idade, do gênero, do estado civil e do nível de escolarização dos aposentados, do tempo de aposentadoria, do valor da aposentadoria, da sua residência e da renda.
Em relação ao gênero dos entrevistados, sete são mulheres e cinco são homens. Considerando à idade, os aposentados entrevistados estão na faixa entre 56 e 77 anos, apenas um entrevistado não se enquadra na categoria idosos jovens. Em relação ao estado civil, que tem relevância para que se tenha uma ideia da participação de mais de uma pessoa além do próprio idoso na renda domiciliar, observa-se que a pesquisa incluiu três mulheres viúvas, duas mulheres divorciadas, duas mulheres casadas e cinco homens casados. No que se refere ao grau de escolaridade, observa-se que a maior frequência é para o atual ensino fundamental (o que equivale a $1^{\mathrm{a}}$ a $5^{\mathrm{a}}$ série).

Sobre o valor mensal da aposentadoria, sete recebem um salário mínimo e contam com mais alguma complementação na sua renda, como pensão ou alguma atividade remunerada que ainda desempenham. No restante, todos recebem dois salários mínimos ou mais, e ainda incluem alguma renda proveniente ou de pensão ou de trabalho executado depois de aposentados.

\section{Background familiar}

Essa categoria buscou apresentar como o relacionamento do aposentado com a sua família interfere em suas escolhas e, também, como pontuam nos seus hábitos, cultura e comportamento em geral.

A partir da pesquisa, foi constatado que nenhum aposentado entrevistado mora sozinho. Os aposentados entrevistados moram com os filhos, normalmente maiores de idade, além de, em alguns casos, morarem com os netos. Como foi 
visto anteriormente, essa realidade vai ao encontro das constatações apontadas por Camarano et al. (2004b), que chamam a atenção para o papel das famílias extensas ou estendidas ${ }^{5}$. Essas podem incluir, além dos filhos, os netos ou outros parentes próximos, como pode ser observado pela fala dos entrevistados sobre sua unidade familiar.

Uma aposentada relata sentir-se sozinha, mesmo morando com o filho. Outra aposentada informa que mora no mesmo terreno em que a neta construiu uma casa e, pelo relato, pode-se perceber que ela sentia-se segura pelo fato de a neta residir no mesmo espaço físico. Outra divide a casa com a filha, entretanto, destaca que há uma separação física no ambiente. Uma das entrevistadas mora com dois filhos maiores de idade na mesma casa e com uma neta, e, pela entrevista, percebe-se que ela não se sente incomodada com isso, pelo contrário, demonstra gostar da situação. Um dos aposentados relata que o neto prefere morar em sua casa antes que na casa do próprio pai, que é ao lado da casa dele. Nesse caso, $o$ aposentado assume nitidamente o papel de pai para o seu neto. Os aposentados que moram somente com a esposa são três. Outro entrevistado comenta que cuida das netas, que moram com ele ao invés de morar com os pais, ou seja, esses idosos que já criaram seus filhos agora criam os netos.

As falas sugerem que o aposentado está vinculado à família e valoriza a presença dos filhos e netos. Essas situações podem ser avaliadas em termos da hipótese da compensação parental (SAAD, 2004, p. 172): os pais prestam auxílio aos filhos quando eles são crianças e os pais receberiam essa ajuda nas idades mais avançadas. $\mathrm{Na}$ maioria dos relatos, os aposentados informam nunca terem precisado pedir ajuda aos filhos. Em poucos casos, eles comentam que os filhos que moravam na mesma residência contribuíam parcialmente para o sustento.

Camarano, Kanso e Mello (2004a, p. 65) ressaltam que a importância de se analisar o rendimento dos idosos está no fato de esse representar uma parcela importante de sua renda: em torno de $37,1 \%$ da renda dos homens idosos, como apontam as autoras, a qual, por sua vez, tem um significado importante na renda das famílias em que estão inseridos. Cabe destacar, nesses termos, a importância da solidariedade familiar, tanto afetiva quanto financeira, que constitui a base das relações familiares. Como descrevem Oliveira e Silva (2012), identifica-se a solidariedade afetiva nas atividades do cotidiano, citam-se o levar e buscar os netos na escola, o levar ao médico e o auxílio nas tarefas domésticas; já a solidariedade financeira pode ser notada pelo pagamento de estudos, pela quitação de contas domésticas (água, luz, telefone, condomínio, supermercado) e pelos empréstimos em dinheiro.

Pelo que foi relatado nas entrevistas, os aposentados sentem-se empoderados, tanto por não precisarem da ajuda dos filhos, quanto por poderem prestar ajuda a eles, corroborando para a presença de solidariedade financeira entre os membros da família. Muitos entrevistados alegam que nunca pediram ajuda, mas comentam que acreditam que, caso fosse necessário, os filhos ajudariam. 


\section{Finalidade do crédito}

Barracho (2001, p. 80) explica que a motivação pode ser definida como uma estrutura do comportamento, mediante a qual o organismo é instigado a atender as suas necessidades, o que pode ser relacionado ao fato de o aposentado buscar o crédito, para que suas necessidades sejam satisfeitas. Os processos motivacional e informacional de cada indivíduo determinam o seu comportamento. A esse respeito, resultados de avaliações e experimentos demonstram que a informação, no processo de tomada de decisão, como destaca Peters (2010), é utilizada em dois modos diferentes de pensamento: um sistema afetivo/experimental e outro sistema deliberativo, ambos decisivos. Explica que o modo experimental está associado a pensamentos e sentimentos de modo espontâneo, sem esforço, com operações implícitas, intuitivas, automáticas, associativas e rápidas, portanto, baseado em sentimentos afetivos/emocionais. Já o modo deliberativo, ao contrário, é consciente, analítico, baseado na razão, verbal e relativamente lento e é ele que é mais flexível e fornece controle aos processos experienciais mais espontâneos. Em princípio, os adultos mais velhos apresentariam declínio no modo deliberativo, implicando em decisões piores em relação aos adultos mais jovens. Todavia, acrescentam que evidências demonstram que os adultos mais velhos parecem usar sua capacidade deliberativa de modo mais seletivo, a experiência acumulada pode compensar parcialmente os declínios decorrentes da idade e, por fim, o foco emocional aumen- ta com a idade. Tais fatos, de acordo com $o$ autor, permitem inferir que os adultos mais velhos tomem decisões melhores em relações aos mais jovens, sobretudo em relação a questões vitais, como saúde, finanças e outras questões pessoais.

Malucelli (2008, p.67) destaca a participação do aposentado como um tomador de crédito. A autora descreve que, em um levantamento efetuado pelo Banco Central do Brasil, constatou-se que a maioria dos consumidores que se beneficiam do crédito consignado são os idosos aposentados do INSS. No período entre 2006 e 2012 , a quantidade de transações por empréstimo consignado para aposentados e pensionistas do INSS passou de 4.821.866 para 11.817 .344 , um aumento de $145,1 \%$ (BRASIL, MS, 2013). Cabe atentar para o fato de que, esses idosos, em estado de especial vulnerabilidade, não poucas vezes, como afirma Malucelli (2008), são coagidos pelos familiares a assumirem empréstimos e acabam fazendo isso com medo de perder $o$ afeto de seus filhos, netos, entre outros. Os motivos para a aquisição do crédito são vários, entretanto, comenta a autora, muitas vezes, os familiares acabam pedindo o dinheiro, ou dando a entender que precisam de dinheiro e os idosos acabam oferecendo o dinheiro sem expectativas de receberem de volta.

A Secretaria Especial de Direitos Humanos (SEDH) implementou recentemente um Plano de Ação para o Enfrentamento da Violência da Pessoa Idosa, sendo a proteção em relação ao abuso econômico e financeiro uma das ações (BRASIL. Presidência da República. SEDH, 2007). Parte dessa vulnerabilidade, de outra 
parte, é explicada pelo próprio sistema financeiro. Algumas irregularidades ou situações adversas evidenciadas em relação à forma de contratação, a clareza e a transparência nas informações, o teto de juros, a possibilidade de arrependimento e o superendividamento, decorrentes do crédito consignado, conduziram à atuação dos Ministérios da Previdência Social, da Justiça e da Fazenda, juntamente com entidades representativas da categoria e do Procon, no sentido da regulação do segmento, contribuindo para proporcionar segurança jurídica aos requerentes (GOMES, 2011).

Pressupõe-se que o crédito consignado, para os aposentados brasileiros, esteja sendo utilizado para prover despesas correntes, considerando que, em muitos casos, o valor do benefício previdenciário é insuficiente, ou mesmo para despesas com serviços de saúde. Existe a possibilidade de, com os descontos na origem, as dificuldades para prover as despesas correntes sejam ainda maiores, o que levaria ao aposentado utilizar o sistema financeiro para novos empréstimos, com risco de superendividamento.

Os relatos dos aposentados pesquisados sinalizam que, por diferentes motivações, o acesso ao crédito consignado tem sido frequente: "Não me lembro, já fiz um monte de vez" (B, 68, mulher). "Não lembro agora, já fiz uns quantos" (J, 63, homem).

A primeira vez, a primeira vez eu acho que... barbaridade... eu não me lembro bem quando fiz... mas eu fazia bastante... mas três quatro vezes eu já fiz... mas eu possuo aquele ali que eu fiz e depois renovei porque comprei o trator para trabalhar no mato. Daí precisei do dinheiro (O, 62, homem).
Os argumentos dos aposentados, ao mencionarem não recordar quantas vezes já assumiram o empréstimo, sugerem que o crédito consignado tem se tornado uma prática normal, um hábito entre eles. Percebe-se que poucos tomaram o empréstimo apenas uma vez.

Outras falas indicam que os aposentados defrontam-se com dificuldades para viver com o valor recebido com a aposentadoria. "Possuo, a gente se aperta... daí tem que pega" ( $\mathrm{D}, 69$, mulher). Uma aposentada informa que tomou o empréstimo somente pelo fato de que pagava aluguel e sua aposentadoria não chegava para tudo. Entretanto, ela não comenta sobre como vive agora com o desconto da parcela, o que pode lhe custar ainda mais dificuldades. "É que eu tava apertada... e eu pagava aluguel, e eu morava la embaixo... Daí eu fiz o empréstimo, mas não de muito... mil e poco... mil e duzentos... foi o máximo, eu acho" (N, 67 , mulher). Outras explicam que o que elas recebem de benefício previdenciário não basta para cobrir suas despesas: "Olha... quando o que eu ganhava não dava pra pagar dívidas que eu tinha foi uma maneira de procurar sanar esse problema e... graças a Deus... eu consegui... paguei direitinho o empréstimo, já me livrei de um e agora tenho mais um". (E, 77, mulher). "Sim eu me apertava né? A gente ganha aquilo... tem que faze empréstimo, senão tu não consegue nada direito... Empréstimo que ajuda a gente né?" (B, 68 , mulher). Portanto, a insuficiência do poder de compra dos benefícios recebidos configura-se como uma motivação para a tomada do crédito consignado por parte dos aposentados pesquisados. 
Observa-se, de outra parte, o motivo relacionado à saúde: "Só quando precisamos, por causa de saúde... eu esperei caso eu precisasse" (L, 56, homem). Outros aposentados entrevistados referem ter tomado o crédito consignado para trocar de carro ou para pagar por benfeitorias públicas, como o calçamento da rua, que estava em construção.

Chama a atenção o relato daqueles que associam a tomada do crédito para a necessidade da família. Uma aposentada diz ter tomado o crédito para o seu genro e, além de admitir o motivo, ela complementa que ele e a filha estão pagando certinho, e ela não se arrepende da decisão. Outra entrevistada, que também tomou crédito para ajudar a família, comenta que estavam usando um empréstimo com juro mais alto e que decidiu fazer o empréstimo consignado para ajudar o filho e, além disso, vê a fase do empréstimo como uma etapa que foi vencida na sua vida:

O momento foi a dificuldade, que eu estava passando... O meu filho não estava trabalhando, então eu tinha que mandar um dinheiro para ele... a coisa começou a apertar, eu estava quase sempre no cheque especial, mas graças à Deus isso foi vencido (E, 77, mulher).

Outra aposentada pesquisada argumenta que foi por causa de problemas financeiros da filha que ela resolveu ajudar, ou seja, nesse caso quem influenciou na sua decisão foi a filha. Entretanto, quando ela foi indagada sobre a demanda da filha ela ressaltou que esta não pediu o dinheiro, que ela resolveu ajudá-la de "livre e espontânea vontade". Segundo ela, a filha lhe disse que não queria que ela se endividasse, depois que a idosa contou o que havia feito. "Acho que foi em 2007, por problemas financeiros mesmo, aquela vez, quando a filha se separou né... daí eu tive que ajuda ela, daí a gente apelo por isso ali, né" (X, 61, mulher).

Sobre a necessidade e a influência na hora de tomar empréstimo, nenhum aposentado assume ter sido influenciado por alguém: todos, até os que referem ter tomado empréstimo para a família, afirmam que não foram coagidos ou obrigados a assumi-lo. Uma das aposentadas entrevistadas, nesse sentido, explica que tomou o crédito por necessidade. "Não... influenciada não... o que me influenciou foi a necessidade" ( $\mathrm{E}, 77$, mulher). Um dos aposentados acrescenta, inclusive, que a família era contra o fato de ele tomar o crédito. "Não... a minha família nem queria que eu fizesse" (L, 56, homem). De outra parte, uma justificativa feita por uma das aposentadas é que ajudava os filhos porque, no futuro, quando ela vier a faltar, as coisas que ela adquiriu ao longo da vida, também, serão deles.

Uma situação inusitada foi a de uma aposentada que, em seu depoimento, relata que o empréstimo era uma "ajuda" oferecida pelas instituições financeiras, uma percepção equivocada de se ver o crédito. Como Neri (2007) aponta, trazendo dados de uma pesquisa, $23,0 \%$ dos idosos não conhecem o crédito consignado e realmente pode-se constatar que, na prática, os aposentados não conhecem por completo o crédito consignado antes da aquisição. $O$ crédito consignado é de fácil acesso. Todavia, o crédito deve ser dosado de maneira certa para que não 
proporcione um endividamento ainda maior envolvendo o aposentado ou pensionista do INSS.

Os aposentados justificam o fato de não planejarem a tomada do empréstimo por estarem diante de uma necessidade urgente em contar com o recurso, ou seja, não poderiam esperar, demonstrando um comportamento voltado para o presente, imediato. A média dos valores tomados por todos os aposentados fica em torno de $\mathrm{R} \$ 3.900,00$ e em prazos que variam de 18 a 72 meses, sendo que o mais frequente foi superior a 36 meses. Constata-se que, comparativamente aos rendimentos, o grau de comprometimento da renda com o empréstimo consignado é significativo, sobretudo pelo prazo em que esse é assumido.

Com relação à facilidade de acesso ao crédito, divulgada nos meios de comunicação, observa-se que, em princípio, pode atrair o aposentado, mas que, no decorrer do tempo, depois de assumir o empréstimo ele reavalia.

Não, todas as vezes fui eu que quis... percebia que faltava dinheiro e tinha a facilidade...Só que eu penso que é uma facilidade falsa... porque é fácil para pegar e difícil para pagar ( $\mathrm{P}, 64$, homem).

Malucceli (2008, p. 68) comenta que não são raras as situações em que aposentados são abordados por algumas instituições concessoras de crédito consignado no interior de estabelecimentos bancários, oportunidade em que são informados de que ali está disponível para eles um crédito de valor aprovado. Acontece, também, por falta de orientação e de instrução que os beneficiários, na grande maioria das vezes sem entender, como comenta a autora, aceitam o crédito oferecido sem nenhum esclarecimento do que aquele ato de aceitação virá a lhes acarretar. Exemplifica que existem casos em que o beneficiario sequer suspeita que está tomando um empréstimo.

Cabe observar, como destaca a autora, que as instituições financeiras têm a obrigação de informar e aconselhar sobre os benefícios e o ônus do crédito, pois se baseiam na confiança necessária que o consumidor deposita no profissional que detém os conhecimentos técnicos da operação de crédito ofertada. Argumenta, ainda, que duas características marcam o correto cumprimento desses deveres, anexos à boa-fé: a veracidade das informações e a lealdade.

Os relatos obtidos da pesquisa indicam que a divulgação dessa possibilidade de crédito influencia na tomada de decisão dos aposentados, sobretudo no sentido da sua percepção como um sujeito que dispõe autonomia e credibilidade para assumi-las. Os resultados da pesquisa indicam que os aposentados podem contar com esse recurso financeiro para proverem as despesas que o benefício previdenciário não cobre ou para auxiliarem os seus familiares. Entram em cena, no processo de tomada de decisão, tanto as atitudes impulsionadas pelo sistema afetivo, quanto aquelas requeridas no contexto de solidariedade financeira, no âmbito familiar.

\section{Considerações finais}

A discussão sobre o processo de envelhecimento demonstra que a literatura explicita que se trata de um processo multidimensional, no qual o indivíduo 
necessita de ações preventivas para a manutenção de suas capacidades físicas, mentais, sociais e econômicas. Outro aspecto fundamental no processo é o apoio intergeracional, com o foco na família, evidenciando que não são apenas os idosos que necessitam de suporte dos filhos, mas os filhos também têm necessitado de auxílio dos seus pais idosos.

No âmbito da tomada de decisão, observa-se que todos os indivíduos fazem escolhas, a partir de experiências passadas, colocando em foco tanto os sistemas emocional quanto deliberativos, modo pelo qual são formadas suas preferências e que, com o crédito não é diferente. Os fatores psicológicos, por meio das motivações individuais, são definidores das ações. Com a pesquisa aplicada foram identificadas diversas questões que corroboram com achados da literatura.

Quanto às características pessoais dos idosos aposentados, na tomada de crédito, pode-se perceber que indivíduos com diferentes níveis de escolarização adquirem o crédito. Em relação à idade, confirma-se resultados de pesquisas anteriores que relataram que os idosos jovens (de 65 a 74 anos) tem uma demanda superior por crédito consignado, em relação aos demais idosos.

Com relação às estruturas familiares, a particularidade dos idosos entrevistados foi de serem principais provedores da renda familiar, o que demonstra a preservação de seu poder ou força em relação aos demais membros. Em alguns casos os filhos recorrem a eles como uma maneira de financiar seus projetos, dívidas, necessidades, reforçando os laços de confiança na unidade familiar e corroborando com a importância da solidariedade financeira entre eles.

No que diz respeito aos fatores psicológicos dos aposentados pesquisados, na tomada do crédito, percebe-se que eles se sentem empoderados, principalmente quando emprestam dinheiro aos filhos. Um fato interessante que se observa é que esses idosos justificam a tomada do crédito pela necessidade, comentando que não gastaram de forma impensada ou inconsequente. Nas situações em que tomaram o crédito para auxiliar os filhos, manifestam sentimento de obrigação para com eles, no sentido de apoio intergeracional. Os filhos representam, em suas percepções, a extensão de suas vidas, a continuidade da família.

Por fim, embora os motivos para a aquisição de crédito dos idosos pesquisados estejam relacionados a diversos fatores e que a situação econômica da família tem peso significativo, a possibilidade de tomar ou assumir o crédito parece garantir a sua autonomia. De outra parte, esta possibilidade de acesso ao crédito, para amenizar os seus problemas financeiros, o processo recorrente de tomada de crédito, deve ser contextualizado em relação aos riscos de endividamento. 


\section{Between reason and emotion: making consigned credit for the elderly}

Students of economic psychology have been trying to establish the relationship between consumption and behavior. Understanding the emotions that people experience and influences, at time consuming, or postpone consumption, becomes critical when analyzing decision making. Consigned credit have been a type of loan very used by elderly, on the one hand signaling easy access on the other implies indebtedness. The objective of this article is to ascertain the reasons why the retiree making consigned credit. The study is descriptive with qualitative approach and presents the content analysis results from 12 interviews with retirees of city Não-Me-Toque (RS) who had taken make consigned credit. Concludes that the retiree has researched the possibility of taking consigned credit as an everyday choice and claims to be autonomous in decision although, in most cases, takes the debt to assist families who are in difficulty. The affective system and economic solidarity within the family have considerable weight in the decision making.

Keywords: Human Aging. Economic psychology. Consigned Credit. Indebtedness.

\section{Notas}

1 O crédito consignado foi instituído pela Lei $\mathrm{n}$. 10.820, de 17 de dezembro de 2003 (RODRIGUES et al., 2005). Essa lei autoriza a Caixa Econômica Federal, em um primeiro momento, a disponibilizar uma modalidade de crédito no qual o trabalhador, regido pela Consolidação de Leis Trabalhistas, ou aposentados e pensionistas, poderá contratar o empréstimo. O desconto ocorre diretamente em sua folha de pagamento e esse valor poderá corresponder a $30,0 \%$ do salário, sendo pago pela empresa e descontado do salário diretamente

2 Risco moral ou moral hazard, é um conceito utilizado pela economia comportamental que diz respeito à falta de qualquer incentivo para se proteger contra um risco quando o indivíduo está protegido contra ele.
3 Os nomes que marcam a historia da psicologia econômica são: Grabriel Tarde e Thorstein Veblen, final século XIX e início do século XX; George Katona e Pierre-Louis Reynaud, na metade do século XX; Herbert Simone Daniel Kahneman, premiados pelo Nobel de Economia, no século XX. Katona é considerado o pioneiro da psicologia econômica moderna (FERREIRA, 2008).

4 O projeto de pesquisa que deu origem ao artigo não passou pelo Comitê de Ética e Pesquisa da Instituição, pois na unidade acadêmica em que foi desenvolvido não havia tal exigência. Os pesquisadores assumem toda a responsabilidade pelas questões éticas envolvidas, assim como possíveis desconfortos emocionais durante a aplicação da pesquisa.

5 De acordo com o IBGE (2011, p. 20), uma família "estendida é constituída somente pela pessoa responsável com pelo menos um parente, formando uma família que não se enquadre em um dos tipos descritos como nuclear".

\section{Referências}

ALMEIDA, Priscila M. de; MOCHEL, Elba, G.; OLIVEIRA, Maria do S. S. O idoso pelo próprio idoso: percepção de si e de sua qualidade de vida. Kairós, São Paulo. v. 13. n. 2, p. 99-113, mar. 2011.

BARDIN, Laurence. Análise de Conteúdo. v. 70 . Lisboa, 2000.

BARRACHO, Carlos. Lições de psicologia econômica. 2. ed. rev. e amp. Lisboa: Instituto Piaget, 2001.

BRASIL. Ministério da Justiça. Superior Tribunal de Justiça. Crédito consignado cai no gosto do trabalhador e vira tema de decisões no STJ. Artigo especial. Brasília, 2011. Disponível em: <http://www.stj.jus.br/portal_stj/ publicacao/engine.wsp?tmp.area $=398 \&$ tmp. texto $=103651 \& \mathrm{tmp}$.area_anterior $=44 \& \mathrm{tmp}$. argumento_pesquisa $=\mathrm{cr} \% \mathrm{E} 9$ dito $\% 20 \mathrm{consig}$ nado>. Acesso em: 10 jun. 2012.

Ministério da Saúde - MS. Instituto Nacional de Seguridade Social - INSS. Conteúdo Dinâmico. Brasília. 2012. Disponível em: <http://www.previdencia.gov.br/ conteudoDinamico.php?id=18>. Acesso em: 10 jun. 2012. 
Ministério da Saúde - MS. Instituto Nacional de Seguridade Social - INSS. Crédito Consignado. Tabelas. Brasília, 2013. Disponível em: <http://www.previdencia.gov.br/ noticias/categoria/emprestimo-consignado/>. Acesso em: 20 nov. 2013.

. Presidência da República. Secretaria Especial dos Direitos Humanos - SEDH. Plano de Ação para Enfrentamento da Violência contra a Pessoa Idosa. Brasília, 2007. Disponível em: <http://www.observatorionacionaldoidoso.fiocruz.br/biblioteca/_manual/11.pdf>. Acesso em: 15 set. 2013.

CAMARANO, Ana M.; KANSO, Solange; MELLO, Juliana L. Como vive o idoso Brasileiro? In: CAMARANO, Ana M. Os novos idosos Brasileiros muito além dos 60. Rio de Janeiro: Instituto de Economia Aplicada, 2004a. p. 25-75.

CAMARANO, Ana M.; KANSO, Solange; MELLO, Juliana L. PASINATO, Maria T. Famílias: espaço de compartilhamentos de recursos e vulnerabilidades.In: CAMARANO, Ana M. Os novos idosos Brasileiros muito além dos 60. Rio de Janeiro: Instituto de Economia Aplicada, 2004b. p. 137-169

CAMARANO, Ana M.; KANSO, Solange. MELLO, Juliana L. Quão Além dos 60 poderão viver os idosos brasileiros? In: CAMARANO, Ana, M. Os novos idosos Brasileiros muito além dos 60. Rio de Janeiro: Instituto de Economia Aplicada, 2004c. p. 77-134.

CAMARARANO, Ana M.; PASINATO, Maria T. Como vive o idoso Brasileiro? Características sociodemográficas da população idosa. In: CAMARANO, Ana, M. Os novos idosos Brasileiros muito além dos 60. Rio de Janeiro: Instituto de Economia Aplicada, 2004. p. 1-22.

CESHIN, Fernanda; ALQUATI, Cristiani; XIMENES, Maria. Qualidade de vida na velhice. Revista Portal da Divulgação, São Paulo, v. 23, n. 20, p. 1-4, abr. 2012.
FELIX, Jorge. Economia da Longevidade: uma revisão da bibliografia brasileira sobre o envelhecimento populacional. In: Encontro da Associação Brasileira de Economia da Saúde, 8, 2007. São Paulo. Anais... São Paulo. 2007. p. 1-17. Disponível em: <http:// www.observatorionacionaldoidoso.fiocruz. br/biblioteca/_artigos/45.pdf>. Acesso em: 12 set. 2012.

FERREIRA, Vera, R de M. Psicologia Econômica: estudo do comportamento econômico e da tomada de decisão. São Paulo: Elsevier, 2008.

GOMES, Álvaro Edauto da S. Crédito Consignado: medidas corretivas para evitar o superendividamento. Revista FMU Direito, São Paulo, v. 25, n. 35, p. 1-10, 2011.

INSTITUTO BRASILEIRO DE GEOGRAFIA E ESTATÍSTICA - IBGE. Cidades@. Rio de Janeiro, 2012. Disponível em: <http://www. ibge.gov.br/home/> Acesso em: 1 maio 2012.

KATONA, George. Psychological Economics. New York/Oxford/Amsterdam: Elsevier, 1976.

LIMA, Ângela M. M. de; SILVA, Henrique S. da; GALHARDONI, Ricardo. Envelhecimento bem sucedido trajetórias de um constructo e novas fronteiras. Interface-Comunicação, São Paulo, v. 12, n. 27, p. 795-807, out./dez. 2008.

MALUCELLI, Andressa Pacenko. Crédito Consignado: Função Social e Superendividamento. 2008. Dissertação (Programa de Pós Graduação em Direito) - Pontifícia Universidade Católica do Paraná. Curitiba, 2008. Disponível em: <http://www.dominiopublico. gov.br/download/texto/cp047399.pdf>. Acesso em: 10 jun 2012 .

NERI, Marcelo C. Renda, consumo e aposentadoria: evidências, atitudes e percepções. Ensaios Econômicos da EPGE, Escola de Pós Graduação em Economia. São Paulo: FGV. 2007. Disponível em: <http://bibliotecadigital.fgv.br/dspace/handle/10438/473>. Acesso em: 24 nov. 2012. 
OLIVEIRA, Márcia B. de O.; SILVA, Neuza M. da. Participação de aposentados nas transferências de recursos nas famílias. Revista de C. Humanas, Viçosa, v. 12, n. 1, p. 135-144, jan./jun. 2012.

PETERS, Ellen. Aging-Related Changes in Decision Making. In: DROLET, Aimee; SCHWARZ, Norbert; YOON, Carolyn. The aging consumer: perspectives from psychology and economics. New York/Holes: Routledge, 2010. p. 75-101.

SAAD, Paulo M. Transferências de apoio Inter geracional no Brasil e na América Latina. In: CAMARANO, Ana, M. Os novos idosos Brasileiros muito além dos 60. Rio de Janeiro: Instituto de Economia Aplicada, 2004. p. 169-210.

SCHNEIDER, Rodolfo, H.; IRIGARAY, Tatiana $Q$. $O$ envelhecimento na atualidade: aspectos cronológicos, biológicos, psicológicos e sociais. Estudos de Psicologia, Campinas-SP, v. 25, n. 4, p. 585-593, out./dez. 2008. 